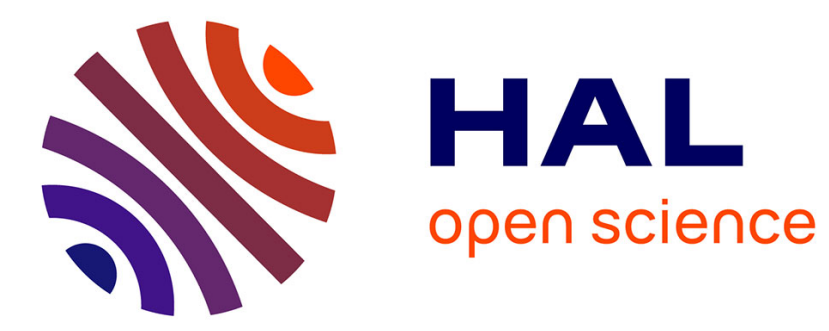

\title{
Efficient Design Using Successive Analytical Subproblems Method: Application to Axial Magnetic Couplings
}

Julien Fontchastagner, Thierry Lubin, Frédéric Messine, Smaïl Mezani

\section{- To cite this version:}

Julien Fontchastagner, Thierry Lubin, Frédéric Messine, Smaïl Mezani. Efficient Design Using Successive Analytical Subproblems Method: Application to Axial Magnetic Couplings. IEEE Transactions on Magnetics, 2015, 51 (3), 4 p. 10.1109/TMAG.2014.2357055 . hal-01064154

\section{HAL Id: hal-01064154 \\ https://hal.science/hal-01064154}

Submitted on 15 Sep 2014

HAL is a multi-disciplinary open access archive for the deposit and dissemination of scientific research documents, whether they are published or not. The documents may come from teaching and research institutions in France or abroad, or from public or private research centers.
L'archive ouverte pluridisciplinaire HAL, est destinée au dépôt et à la diffusion de documents scientifiques de niveau recherche, publiés ou non, émanant des établissements d'enseignement et de recherche français ou étrangers, des laboratoires publics ou privés. 


\title{
Efficient Design Using Successive Analytical Subproblems Method: Application to Axial Magnetic Couplings
}

\author{
Julien Fontchastagner ${ }^{1}$, Thierry Lubin ${ }^{1}$, Frédéric Messine ${ }^{2}$, and Smaïl Mezani ${ }^{1}$ \\ ${ }^{1}$ Université de Lorraine, GREEN, Vandouvre-lès-Nancy, F-54500, France \\ ${ }^{2}$ Université de Toulouse, ENSEEIHT-LAPLACE, Toulouse, F-31000, France
}

\begin{abstract}
The authors propose a simple but efficient method for design problems. Instead of using directly a heavy numerical code in an optimization process, we successively define some approximated subproblems thanks to an appropriate analytical model. These subproblems can then be solved exactly by a deterministic global optimization solver and the procedure is updated until the approximation matches a 3D FEM computation. The method is applied to an axial magnetic coupling. Comparative results show the effectiveness of this approach, and real design cases are studied thanks to this method.
\end{abstract}

Index Terms-Design, Axial magnetic coupling, Global optimization, Successive analytical subproblems.

\section{INTRODUCTION}

$\mathbf{S}$ INCE around thirty years, it becomes usual to formalize design problems as optimization ones, generally defined as MINLP problems (mixed integer non-linear programs) [1]. When the behavior of the considered device is defined by a purely explicit analytical model, such design problems can be solved exactly by a global deterministic algorithm (based on interval arithmetic) as in [1] or [2].

However some criteria or constraints are often defined thanks to a numerical model and the resulting problem can become hard to solve. The authors present in this paper a simple but efficient technique to solve this kind of design problems when an analytical approximation exists.

\section{Axial Magnetic Couplings}

A basic structure of an axial magnetic coupling is considered as shown in Fig.1. It consists in two rings of permanent magnets, with alternatively north and south poles glued on two flat iron cylinders. The whole geometry is defined with six parameters (five real numbers and one integer) listed in Table. I. One real physical parameter is also added: $B_{r}$ the remanence of the magnets.



Fig. 1. Geometry of the studied structure (only 2 poles)

In this work, we focus on the steady-state behavior of the coupling. The two parts, the driving and the driven ones rotate at a synchronous constant speed. Thus, it is assumed that there is no Foucault's current in the magnets or in the yokes.
TABLE I

PARAMETERS USED TO DESCRIBE COUPLINGS

\begin{tabular}{c|c|c}
\hline Name & Description & Unit \\
\hline \hline$R_{1}$ & Outer radius of magnets & $\mathrm{mm}$ \\
$R_{2}$ & Inner radius of magnets & $\mathrm{mm}$ \\
$h$ & Magnets thickness & $\mathrm{mm}$ \\
$e$ & Air-gap length & $\mathrm{mm}$ \\
$\alpha$ & PMs pole-arc to pole-pitch ratio & $\in[0,1]$ \\
$p$ & Pole-pairs number & $\in \mathbb{N}$ \\
$B_{r}$ & Remanence of magnets & $\mathrm{T}$ \\
\hline
\end{tabular}

\section{A. Analytical Modeling}

In [3], the authors develop, test and use a complete analytical explicit model for such a structure. So it is possible to compute the electromagnetic torque very quickly. This model is based on an analytical resolution of the magnetic vector potential by separating the variables. If only the first harmonic is considered, and after simplifications, the electromagnetic torque is provided by:

$$
\Gamma_{\text {ana }}=\frac{16 B_{r}^{2}}{3 \pi \mu_{0}}\left(R_{2}^{3}-R_{1}^{3}\right) \sin ^{2}\left(\alpha \frac{\pi}{2}\right) \frac{\sinh ^{2}(a) \sin (p \delta)}{\sinh (2(1+\nu) a)}
$$

with

$$
a=p \frac{2 h}{R_{1}+R_{2}} \quad \text { and } \quad \nu=\frac{e}{2 h} .
$$

$\mu_{0}$ is the permeability of vacuum and $\delta$ is the relative angular position between the magnets of the lower side with those of the upper side. Then the maximum torque value is obtained when $\delta=\frac{\pi}{2 p}$.

Such a model can be really useful in order to determine the influence of given quantities with parametric variations as in [3] or [4]. Nevertheless the obtained torque value is generally overestimated as shown in section II-C.

\section{B. Numerical Computation of the Electromagnetic Torque}

A 3D FEM model is much suitable in order to reach a better accuracy on the torque computation. The strong formulation 
of the problem corresponding to the scalar magnetic potential $U_{m}$ is given by:

$$
\operatorname{div}\left(\mu \operatorname{grad} U_{m}-\mathbf{B}_{\mathbf{r}}\right)=0,
$$

where $\mu$ is the permeability in the considered region (air, magnet or iron), $\mathbf{B}_{\mathbf{r}}=\left(0,0, \pm B_{r}\right)$ in the magnets and $(0,0,0)$ in the rest of the domain.

The thickness of iron yokes $\left(h_{y}\right)$ is computed from parameters values thanks to a simple analytical formula (3) based on Ampère's law and flux conservation considerations.

$$
h_{y}=\frac{B_{r}}{B_{c}} \frac{\alpha \pi h}{(2 h+e)} \frac{R_{1}+R_{2}}{2 p}
$$

where $B_{c}$ is the average wished value of the induction in the yoke, the value used in the present work is: $B_{c}=1.5 \mathrm{~T}$.

The problem is solved using the general commercial finite element solver FlexPDE [5]. After the resolution, the induction vector $\mathbf{b}=\left(b_{x}, b_{y}, b_{z}\right)$ in the whole domain is deduced from $U_{m}$. The electromagnetic torque can be computed by applying the Maxwell stress tensor on $S_{z}$, a circular area in the air gap between the magnets with a radius equal to the domain one.

A smart method to avoid numerical noise is to average this surface integral along the air gap. Then, a good approximation of the torque $\Gamma_{3 \mathrm{D}}$ can be given directly by a volume integral on the whole air cylinder between the magnets $V_{a}$ :

$$
\begin{gathered}
\Gamma_{3 \mathrm{D}}=\frac{1}{e} \int_{-e / 2}^{e / 2}\left(\iint_{S_{z}}\left[\left(\begin{array}{l}
x \\
y \\
0
\end{array}\right) \times \frac{1}{\mu_{0}}\left(\begin{array}{c}
b_{x} b_{z} \\
b_{y} b_{z} \\
b_{z}^{2}-\frac{\|\mathbf{b}\|^{2}}{2}
\end{array}\right)\right] \cdot \mathbf{u}_{\mathbf{z}} \mathrm{d} x \mathrm{~d} y\right) \mathrm{d} z \\
=\frac{1}{\mu_{0} e} \iiint_{V_{a}}\left(y b_{x}-x b_{y}\right) b_{z} \mathrm{~d} x \mathrm{~d} y \mathrm{~d} z
\end{gathered}
$$

\section{Models vs. Measurements}

In order to determine the validity of the two previous models a comparison with experimental values is performed. The used coupling is the same prototype described in [3] (with $p=6$ and $\mu=500 \mu_{0} \mathrm{H} \cdot \mathrm{m}^{-1}$ ), see Fig. 2.



Fig. 2. Axial magnetic coupling prototype placed on the test bench

The torque values measured on the bench and those computed by the two models are plotted on Fig. 3. The abscissa corresponds to the angular displacement in mechanical degrees, and is then equal to $\frac{180}{\pi} \delta$. The maximum torque value is reached when this angle is equal to 15 degrees which corresponds to $\delta=\frac{\pi}{2 p}$ as seen in II-A. This maximum value is the chosen dimensioning torque value.

It appears clearly that the analytical model gives the right tendencies but overestimates significantly the interesting quantity, e.g. the torque. The 3D FEM model is really much closer



Fig. 3. Models vs. Experimental Values Comparison

to the measurements, and should be the reference estimation in a rigorous design process as described below.

\section{Successive Analytical Subproblems (SAS)}

\section{A. Problem Statement}

The considered design problems to solve can always be written under the form $\left(S_{g}\right)$ defined by:

$$
\left(S_{g}\right)\left\{\begin{array}{l}
\min _{\mathbf{x} \in D} f_{o b j}(\mathbf{x}) \\
\text { s.t. } \quad h_{i}(\mathbf{x})=0, \quad i \in \llbracket 1, n_{h} \rrbracket \\
g_{i}(\mathbf{x}) \leq 0, \quad i \in \llbracket 1, n_{g} \rrbracket
\end{array}\right.
$$

where the objective function $f_{o b j}$ can be the total mass $M_{a}$ for instance, $\mathbf{x}$ is the vector of chosen design variables which can be real ones (as for some dimensions) or integers (as for the pole pair number) or even categorical ones (as kinds of materials). $D$ is the search domain defined by the bound values of these variables. The $h_{i}$ and $g_{i}$ functions define a set of $n_{h}$ equality and $n_{g}$ inequality constraints.

Such problems are called MINLP. In the case where all the functions are purely explicit and analytical the so-formulated global optimization problems can be solved exactly by a particular algorithm, called IBBA for Interval Branch and Bound Algorithm. It is based on a Branch and Bound technique where the bounds are computed using interval analysis, see [1], [2] and [6] for details.

Nevertheless in the present case, a numerical computation of the torque (in a black-box form) should be preferred to the analytical expression as seen in the previous section. Previous work has shown the possibility to use some blackbox constraints with IBBA. But it works only with numerical constraints (not the objective) and with relative fast models (around 1 second), as described in [7]. In the present case, the CPU time of a torque computation is greatly higher. This is why a new simple way of using global deterministic optimization with black-box constraint or objective is presented below.

\section{B. SAS Method}

The idea is to use both advantages of the two modeling tools: swiftness of the analytical and accuracy of the numerical 
one. A corrected analytical model is defined by multiplying the initial model by a corrective factor $\beta_{k}$. This modified model is used as a surrogate one and it makes it possible to compute the torque rapidly. The associated optimization subproblem $\left(S_{k}\right)$ is solved using IBBA. A comparison with 3D FEM for the found minimum is performed, the corrective factor is updated and the procedure iterated until the difference between the two models is less than a fixed tolerance $\varepsilon_{t o l}$.

The method is called SAS (for Successive Analytical Subproblems). In the case where, for instance, the torque defines the first inequality constraint $\left(\Gamma_{3 \mathrm{D}}(\mathbf{x}) \geq \Gamma_{\text {fixed }}\right)$, the corresponding algorithm is given by Algorithm 1 .

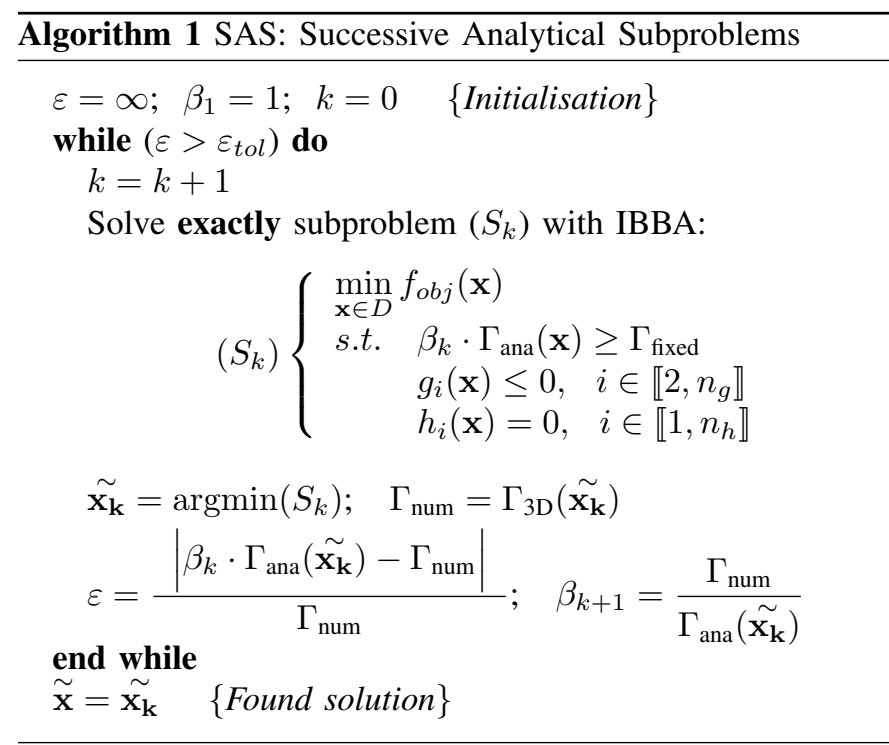

The interest of such a technique lies in its simplicity. Of course, this technique does not permit to ensure with certainty the global exactness of the found solution. Each $\widetilde{\mathbf{x}_{\mathbf{k}}}$ is sure to be exact; for the final $\tilde{\mathbf{x}}$, it depends on the goodness of the analytical model. However, it permits to solve the general problem (5) effectively, as shown thereafter.

\section{NUMERICAL EXPERIMENTS}

\section{A. Realistic design cases}

Some real problems of magnetic coupling design are solved in this section. The chosen variables are:

$$
\mathbf{x}=\left(R_{1}, R_{2}, h, \alpha, p, \sigma_{m}\right)
$$

where $\sigma_{m} \in\{1, \ldots, 5\}$ is a categorical variable representing the kind of magnet material, detailed in Table II. The factor $p_{f}$, given in this table, is a price factor expressed in unit per kilogram. It means that, for example, the $38 \mathrm{M}$ grade is 1.4 times more expensive than the $30 \mathrm{M}$ one. The air-gap length $e$ is not considered as a design variable, for all the numerical tests it is set to $e=5 \mathrm{~mm}$.

The considered problems are all under the following form:

$$
\begin{cases}\min _{\mathbf{x} \in D} f_{o b j}(\mathbf{x}) \\ \text { s.t. } & g_{1}: \Gamma_{3 \mathrm{D}} \geq 100 \mathrm{~N} \cdot \mathrm{m} \\ g_{2}: & R_{2} \leq 0.9 R_{1} \\ g_{3}: & R_{1}(1-\alpha) \frac{\pi}{p} \geq \frac{e}{2} \\ h_{1}: & 180 \cdot \frac{\alpha}{p} \in \mathbb{N}\end{cases}
$$

TABLE II

POSSIBLE KINDS OF MAGNETS [8]

\begin{tabular}{|c|c|c|c|c|c|}
\hline$\sigma_{m}$ & Material & Grade & $B_{r}(\mathrm{~T})$ & $\rho\left(\mathrm{kg} \cdot \mathrm{m}^{-3}\right)$ & $p_{f}\left(\mathrm{~kg}^{-1}\right)$ \\
\hline \hline 1 & & $30 \mathrm{M}$ & 1.08 & & 1.0 \\
2 & & $33 \mathrm{M}$ & 1.13 & & 1.1 \\
3 & \multirow{N}{*}{$\mathrm{NdFeB}$} & $38 \mathrm{M}$ & 1.22 & 7500 & 1.4 \\
4 & & $45 \mathrm{M}$ & 1.32 & & 1.7 \\
5 & & $50 \mathrm{M}$ & 1.40 & & 2.1 \\
\hline
\end{tabular}

where the objective function $f_{o b j}$ can be the volume of magnets $V_{m}$, the global external volume $V_{g}$, the total mass $M_{a}$, or even a cost indicator $c_{i}$ given by the product of the mass of the magnets by the price factor $p_{f} . g_{2}$ and $g_{3}$ are two geometric shape inequality constraints. $h_{1}$ is an equality constraint reflecting the fact that the angular width of the magnet must be an integer: it is a constructability constraint imposed by the chosen manufacturer [8]. The $R_{1}$, $R_{2}$ and $h$ variables have also been imposed to be rounded to the nearest tenth of a millimeter directly in the optimization process. The density of the chosen iron is $7730 \mathrm{~kg} \cdot \mathrm{m}^{-3}$. All the problems have been solved and the obtained results are given in Table III.

TABLE III

\begin{tabular}{|c|c|c|c|c|c|}
\hline & Bounds $(D)$ & $\min V_{m}$ & $\min V_{g}$ & $\min M_{a}$ & $\min c_{i}$ \\
\hline$R_{1}$ & {$[10,100]$} & 100.0 & 79.4 & 94.1 & 100.0 \\
\hline$R_{2}$ & {$[10,90]$} & 79.9 & 32.9 & 28.6 & 71.9 \\
\hline$h$ & {$[3,20]$} & 4.3 & 4.0 & 3.0 & 4.7 \\
\hline$\alpha$ & {$[0.3,0.95]$} & $0.75\left(9^{\circ}\right)$ & $0.73\left(12^{\circ}\right)$ & $0.58\left(7^{\circ}\right)$ & $0.77\left(10^{\circ}\right)$ \\
\hline$p$ & $\llbracket 2,15 \rrbracket$ & 15 & 11 & 15 & 14 \\
\hline$\sigma_{m}$ & $\{1, \ldots, 5\}$ & 5 & 5 & 5 & 2 \\
\hline \multicolumn{2}{|c|}{$\Gamma_{3 \mathrm{D}}(\mathrm{N} \cdot \mathrm{m})$} & 101.7 & 100.6 & 100.9 & 101.2 \\
\hline \multicolumn{2}{|c|}{$\Gamma_{\text {ana }}(\mathrm{N} \cdot \mathrm{m})$} & 141.0 & 121.6 & 118.2 & 131.4 \\
\hline \multicolumn{2}{|c|}{$\beta=\Gamma_{3 \mathrm{D}} / \Gamma_{\text {ana }}$} & 0.721 & 0.827 & 0.854 & 0.770 \\
\hline \multicolumn{2}{|c|}{$V_{m}\left(\mathrm{~cm}^{3}\right)$} & 73.3 & 96.2 & 88.4 & 110.9 \\
\hline \multicolumn{2}{|c|}{$V_{g}\left(\mathrm{~cm}^{3}\right)$} & 689 & 391 & 412 & 684 \\
\hline \multicolumn{2}{|c|}{$M_{a}(\mathrm{~kg})$} & 2.57 & 1.76 & 1.48 & 2.62 \\
\hline \multicolumn{2}{|r|}{$c_{i}$} & 1.15 & 1.52 & 1.39 & 0.91 \\
\hline \multicolumn{2}{|c|}{$\begin{array}{l}\text { n- of 3D Comp. } \\
\text { CPU Time (min) }\end{array}$} & $\begin{array}{c}4 \\
22 ’ 20 ”\end{array}$ & $\begin{array}{c}3 \\
7,14 "\end{array}$ & $\begin{array}{c}2 \\
10,15,\end{array}$ & $\begin{array}{c}4 \\
62,15,\end{array}$ \\
\hline
\end{tabular}

RESULTS OBTAINED BY SAS

All the optima satisfy the constraint imposed to the torque $\left(\Gamma_{3 \mathrm{D}} \geq 100 \mathrm{~N} \cdot \mathrm{m}\right)$. Depending on the chosen criterion, several topologies can appear with different pole pair numbers and magnet grades. As expected, the three first solutions use the strongest magnets $\left(\sigma_{m}=5\right)$. The $\mathrm{CPU}$ time are relatively small, and less than four 3D FEM computations are required to reach each solution. An interesting fact: the less expensive device is not obtained with the cheapest magnet grade.

\section{B. Comparison with other methodologies}

In order to benchmark the efficiency of the developed methodology, a comparison with more classical techniques were performed. Two methodologies are tested:

1) Ga\&Num: The 3D FE model is directly associated to a genetic algorithm (GA), with 30 individuals evolving during 50 generations. 
2) GA\&ANA+SQP\&Num: The problem is first solved using only the analytical model with a GA (the torque is computed by $\left.0.8 \Gamma_{\text {ana }}\right)$. The obtained solution is then used as the starting point of a sequential quadratic programming (SQP) dealing only with the real variables.

Both methodologies are based on GA because their use is still widespread [9], [10]. The MATLAB $\mathrm{R}$ Global Optimization Toolbox implementations have been chosen. The $h 1$ constraint has been removed to ensure the convergence of these algorithms. The obtained results are given in Table IV. The second methodology provides really good results, but it clearly appears that the SAS method is much faster for the same accuracy.

TABLE IV

SAS VS. SOME OTHER TECHNIQUES: $\min M_{a}$ with $\Gamma_{3 \mathrm{D}} \geq 100 \mathrm{~N} \cdot \mathrm{m}$

\begin{tabular}{c||c|c||c|}
\cline { 2 - 4 } \multicolumn{1}{c||}{} & GA\&Num* & $\begin{array}{c}\text { GA\&ANA + } \\
\text { SQP\&Num* }\end{array}$ & SAS \\
\hline \hline$R_{1}$ & 99.173 & 93.086 & 94.1 \\
$R_{2}$ & 20.253 & 34.838 & 28.6 \\
$h$ & 4.429 & 3.798 & 3.0 \\
$\alpha$ & 0.417 & 0.524 & 0.58 \\
$p$ & 14 & 15 & 15 \\
$\sigma_{m}$ & 5 & 5 & 5 \\
\hline$M_{a}(\mathrm{~kg})$ & $\mathbf{1 . 5 7 4}$ & $\mathbf{1 . 4 8 3}$ & $\mathbf{1 . 4 8 3}$ \\
$\Gamma_{3 \mathrm{D}}(\mathrm{N} \cdot \mathrm{m})$ & 100.2 & 100.0 & 100.9 \\
\hline $\mathrm{n}$ - of 3D Comp. & 1533 & 123 & 4 \\
CPU Time & $25 \mathrm{~h} 30$, & $1 \mathrm{~h} 18$ & 10,15, \\
\hline
\end{tabular}

\section{Black-box objective case}

The SAS method can also be applied to solve problems with a black-box objective function, e.g. in the present case maximize the torque. The algorithm is nearly the same as Algorithm 1, except that $f_{o b j}$ is replaced by $-\beta_{k} \cdot \Gamma_{\text {ana }}$ and, in this example, we chose a price limit for the first inequality constraint: $c_{i}(\mathbf{x}) \leq 1$. Results are given in Table $\mathrm{V}$ and are compared to the exact solution of the same problem using only $\Gamma_{\text {ana }}$ as the objective function.

TABLE V

MAXIMIZATION OF THE TORQUE WITH $c_{i} \leq 1$

\begin{tabular}{|c|c|c|}
\cline { 2 - 3 } & $\begin{array}{c}\text { SAS } \\
\left(\max \Gamma_{3 \mathrm{D}}\right)\end{array}$ & $\begin{array}{c}\text { IBBA } \\
\left(\max \Gamma_{\text {ana }}\right)\end{array}$ \\
\hline \hline$R_{1}, R_{2}, h$ & $100.0,71.0,4.9$ \\
$\alpha, \quad p, \sigma_{m}$ & $0.794\left(11^{\circ}\right), 13,2$ \\
\hline$\Gamma_{3 \mathrm{D}}(\mathrm{N} \cdot \mathrm{m})$ & 108.2 & - \\
$\Gamma_{\text {ana }}(\mathrm{N} \cdot \mathrm{m})$ & \multicolumn{2}{|c|}{141.3} \\
$c_{i}$ & \multicolumn{2}{|c|}{1.00} \\
\cline { 2 - 3 } $\mathrm{n}-$ of 3D Comp. & 2 & 0 \\
CPU Time & 4h 20, 13, \\
\hline
\end{tabular}

The same optimum is found which means two things. Firstly, the analytical model is quite good and really gives the right tendencies. Secondly, the SAS method can find the global optimum which, here, is the solution given by IBBA.

\section{Multi-objective case}

It is also possible to apply the SAS technique sequentially in order to solve multiobjective problems. For instance, Fig. 4 deals with the minimization of the cost $c_{i}$ versus the maximization of the torque $\Gamma_{3 \mathrm{D}}$. Topological groups appear clearly on the obtained Pareto front (57 3D FEM computations, about $10 \mathrm{~h})$.

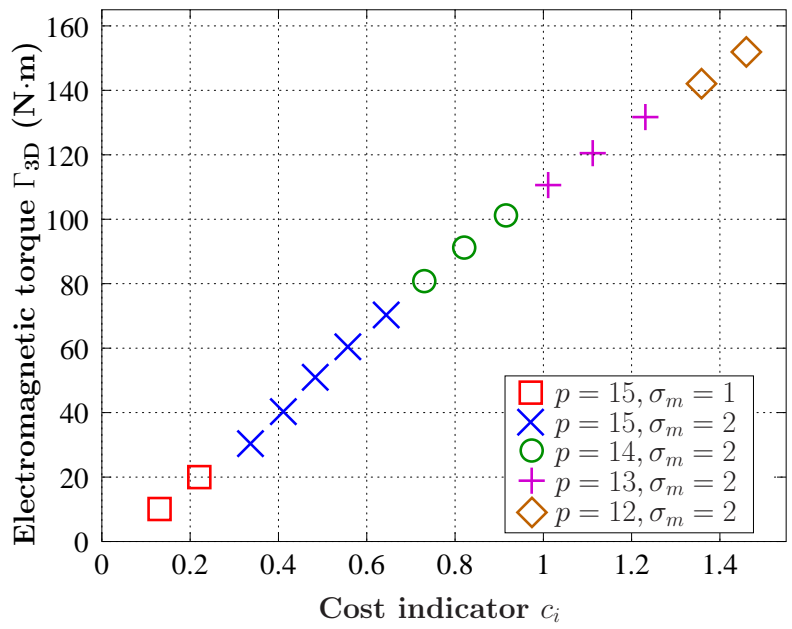

Fig. 4. Pareto front: Cost indicator vs. Electromagnetic torque

\section{CONCLUSION}

In this paper an original and simple method, based on successive analytical subproblems, for solving design problems is presented and applied to an axial magnetic coupling. Many concrete problems are solved using different techniques and numerical results show the efficiency and the interest of this new method SAS.

\section{REFERENCES}

[1] E. Fitan, F. Messine et B. Nogarède, "The electromagnetic actuator design problem: a general and rational approach," IEEE Trans. Magn., vol.40, no.3, pp.1579-1590, 2004.

[2] J. Fontchastagner, Y. Lefèvre and F. Messine, "Some Co-axial Magnetic Couplings Designed Using an Analytical Model and an Exact Global Opti mization Code," IEEE Trans. Magn., vol.45, no.3, pp.1458-1461, 2009.

[3] T. Lubin, S. Mezani and A. Rezzoug, "Simple Analytical Expressions for the Force and Torque of Axial Magnetic Couplings," IEEE Trans. Energy. Convers., vol.27, no.2, pp.536-546, 2012.

[4] H.-J. Shin, J.-Y. Choi, S.-M. Jang and K.-Y. Lim, "Design and Analysis of Axial Permanent Magnet Couplings Based on 3D FEM," IEEE Trans. Magn., vol.49, no.7, pp.3985-3988, 2013.

[5] PDE Solutions Inc, FlexPDE 6 User Manual, Vers. 6.35, 2014.

[6] F. Messine. Essays and Surveys in Global Optimization, Chap.10 "A Deterministic Global Optimization Algorithm for Design Problems," Ed. P. Hansen, and G. Savard, Springer, pp.267-292, 2005.

[7] J. Fontchastagner, F. Messine and Y. Lefèvre, "Design of Electrical Rotating Machines by Associating Deterministic Global Optimization Algorithm With Combinatorial Analytical and Numerical Models," IEEE Trans. Magn., vol.43, no.8, pp.3411-3419, 2007.

[8] HKCM® Engineering e.K, Magnets Segments Online Design, https:// www.hkcm.de, 2014.

[9] A. Mahmoudi, S. Kahourzade, N.A. Rahim and W.P Hew, "Design, Analysis, and Prototyping of an Axial-Flux Permanent Magnet Motor Based on Genetic Algorithm and Finite-Element Analysis," IEEE Trans. Magn., vol.49, no.4, pp.1479,-1492, 2013.

[10] T. Ishikawa, K. Nakayama, N. Kurita and F.P. Dawson, "Optimization of Rotor Topology in PM Synchronous Motors by Genetic Algorithm Considering Cluster of Materials and Cleaning Procedure," IEEE Trans. Magn., vol.50, no.2, pp.637-640, 2014. 